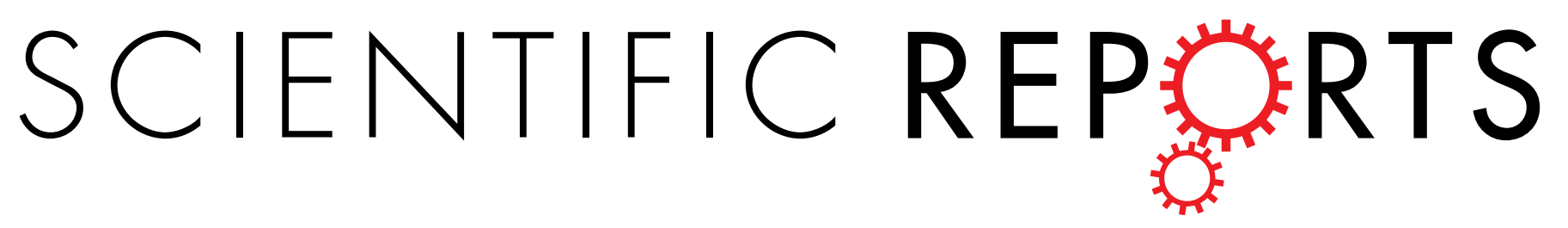

\title{
OPEN Author Correction: Protein corona of airborne nanoscale PM2.5 induces aberrant proliferation of human lung fibroblasts based on a 3D organotypic culture
}

Yan $\mathrm{Li}^{1,3}$, Pengcheng Wang ${ }^{1}$, Chuanlin $\mathrm{Hu}^{6}, \mathrm{Kun} \mathrm{Wang}^{4}$, Qing Chang ${ }^{5}$, Lieju Liu ${ }^{7}$, Zhenggang Han ${ }^{7}$, Yang Shao ${ }^{7}$, Ying Zhai ${ }^{7}$, Zhengyu Zuo ${ }^{7}$, Michael Mak ${ }^{3}$, Zhiyong Gong ${ }^{2}$ \& Yang Wu $\mathbf{W}^{2}$

Correction to: Scientific Reports https://doi.org/10.1038/s41598-018-20445-7, published online 31 January 2018

Michael Mak was omitted from the author list in the original version of this Article. This has been corrected in the PDF and HTML versions of the Article.

The Author Contributions section now reads:

L.Y., M.M., W.Y. and G.Z. conceived and designed the experiments. L.Y., W.P., H.C., C.Q., S.Y., Z.Y. and Z.Z. performed the experiments. L.Y., W.K. and L.L. analysed the data. L.Y., M.M., G.Z. and W.Y. contributed reagents, materials and analysis tools. L.Y., W.Y. and H.Z. took part in the preparation and revision of the manuscript. M.M. provided support for microfluidics and 3D cell culture. All authors have given approval to the final version of the manuscript.

(i) Open Access This article is licensed under a Creative Commons Attribution 4.0 International (c) License, which permits use, sharing, adaptation, distribution and reproduction in any medium or format, as long as you give appropriate credit to the original author(s) and the source, provide a link to the Creative Commons license, and indicate if changes were made. The images or other third party material in this article are included in the article's Creative Commons license, unless indicated otherwise in a credit line to the material. If material is not included in the article's Creative Commons license and your intended use is not permitted by statutory regulation or exceeds the permitted use, you will need to obtain permission directly from the copyright holder. To view a copy of this license, visit http://creativecommons.org/licenses/by/4.0/.

(C) The Author(s) 2018

\footnotetext{
${ }^{1}$ Key Laboratory for Deep Processing of Major Grain and Oil (Wuhan Polytechnic University), Ministry of Education, College of Food Science and Engineering, Wuhan Polytechnic University, Wuhan, 430023, P. R. China. ${ }^{2}$ Hubei Key Laboratory for Processing and Transformation of Agricultural Products (Wuhan Polytechnic University), College of Food Science and Engineering, Wuhan Polytechnic University, Wuhan, 430023, P. R. China. ${ }^{3}$ Department of Biomedical Engineering, School of Engineering \& Applied Science, Yale University, New Haven, 06520, USA. ${ }^{4}$ Division of Biostatistics, Department of Population Health, NewYork University, New York, 10016, USA. ${ }^{5}$ Department of Chemical and Biomolecular Engineering, Hong Kong University of Science \& Technology, ClearWater Bay, Kowloon, Hong Kong. ${ }^{6}$ State Key Laboratory of Silicate Materials for Architectures, Wuhan University of Technology, Wuhan, 430070, P. R. China. ${ }^{7}$ School of Biology and Pharmaceutical Engineering, Wuhan Polytechnic University, Wuhan, 430023, P. R. China. Correspondence and requests for materials should be addressed to Z.G. (email: gongzycn@163.com) orY.W. (email: wuyangwhpu@163.com)
} 